\title{
Effect of Euterpe oleracea Mart. (acai berry) Extract on Skin Flap Survival in Mice
}

\author{
Sangbong Jung ${ }^{1, * *}$, Jongsik Kim ${ }^{2, *}$, Eun-Joong Kim ${ }^{3, * *}$ and Ki-Jong Rhee ${ }^{4, ;, * *}$ \\ ${ }^{I}$ Department of Medical Laboratory Science, Dongeui Institute of Technology, Busan 47230, Korea \\ ${ }^{2}$ Department of Anatomy, College of Medicine, Kosin University, Busan 49104, Korea \\ ${ }^{3}$ Department of Clinical Laboratory Science, Chungbuk Health and Science University, Cheongju 28150, Korea \\ ${ }^{4}$ Department of Biomedical Laboratory Science, Yonsei University MIRAE Campus, Wonju 26493, Korea
}

\begin{abstract}
Skin flap necrosis remains a major complication of reconstructive surgery. Euterpe oleracea Mart., popularly known as "acai berry" contains hydroxybenzoic acid, antioxidant polyphenolics and anthocyanins. These and other compounds within the acai berry confer anti-inflammatory and anti-oxidative effects. In this current study, we evaluated the protective effect of acai berry extracts on survival of random-pattern skin flaps in a murine model by histologic analysis. ICR mice were subjected to skin elevation surgery and orally administered acai berry extract $(100 \mathrm{mg} / \mathrm{kg})$ daily for 7 days. Tissues were stained with hematoxylin-eosin or Masson's trichrome to observe tissue integrity and collagen deposition. In addition, TGF- $\beta$ and VEGF was stained by immunofluorescence to determine anti-inflammatory cell infiltration and neovascularization, respectively. We found a decrease in inflammatory cell infiltration and increase in collagen deposition in the acai berry extract treated mice compared to control mice. Immunofluorescence staining reveal a higher number of TGF- $\beta$ positive cells and enhanced VEGF staining in the acai berry extract treated mice. The results from this study indicate that oral uptake of acai berry extract can promote healing and survival of surgical skin flaps in mice providing an augmentative therapeutic approach to enhancing skin flap survival.
\end{abstract}

Key Words: Skin flap, Euterpe oleracea Mart., Acai berry, Inflammation

Random-pattern skin flaps are widely used in reconstructive plastic surgery. However, development of ischemic necrosis in the distal skin flap is a major concern. Disruption of vascular distribution occurring during inappropriate reconstruction surgery plays a pivotal role in failure of skin flap attachment (Kerrigan, 1983; Atalay et al., 2003). Various studies have shown that pharmacologic drugs such as alpha adrenergic blockers, vasodilators, anti-coagulation agents, prostaglandin E1, free radical scavengers and calcium channel blockers are effective in increasing flap survival (Jurell and Jonsson, 1976; Kjartansson et al., 1988; Ercocen et al., 1998; Davis et al., 1999; Smith and Dolan, 1999). However, prolonged administration of these drugs often lead to severe side effects precluding excessive or long-term doses. Recently, local application of exogenous growth factors such as vascular endothelial growth factor (VEGF) has emerged to augment blood flow and viability of the skin flap (Kryger et al., 2000).

Received: August 5, 2019 / Revised: September 14, 2019 / Accepted: September 16, 2019

* Researcher, ${ }^{* *}$ Professor.

${ }^{\dagger}$ Corresponding author: Ki-Jong Rhee. Department of Biomedical Laboratory Science, Yonsei University Mirae Campus, 1 Yonseidae-gil, Mirae Hall, RM 208, Wonju, Gangwon-do 26493, Korea.

Tel: +82-33-760-2445, Fax:+82-33-760-2561, e-mail: kjrhee@ yonsei.ac.kr

(C) The Korean Society for Biomedical Laboratory Sciences. All rights reserved.

@ (This is an Open Access article distributed under the terms of the Creative Commons Attribution Non-Commercial License (http://creativecommons.org/licenses/by-nc/3.0/) which permits unrestricted non-commercial use, distribution, and reproduction in any medium, provided the original work is properly cited. 


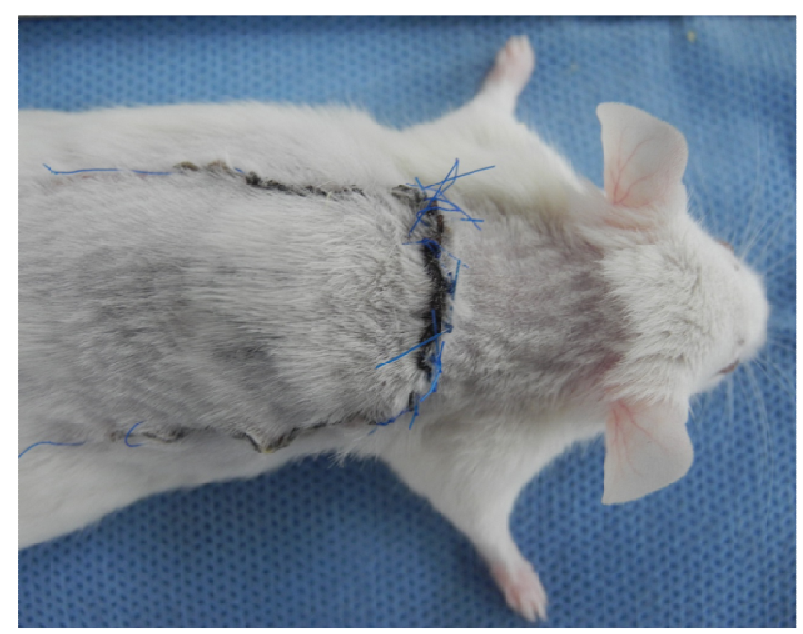

Fig. 1. Post-operative photograph of random pattern skin flap surgery in ICR mice. Photograph was taken on day 7 post-surgery.
Euterpe oleracea Mart. (acai berry) is widely cultivated in the Amazon region of Brazil. Chemical studies have shown that acai berry contains hydroxybenzoic acids, antioxidant polyphenolics, flavan-3-ols, and anthocyanins, predominantly cyanidin 3-O-rutinoside and cyanidin 3-O-glucuronide (Mullen et al., 2002; Pacheco-Palencia et al., 2008; Cassidy et al., 2013). These complex compounds act in concert to inhibit cyclooxygenase- 1 and cyclooxygenase- 2 , inhibit nitric oxide production and promote antioxidative effects (Schauss et al., 2006; Moura et al., 2012). Although the anti-inflammatory, antioxidant and vasodilation effects of acai berry has been shown, to the best of our knowledge, they are no studies on the effects of acai berry on random-pattern skin flap survival (Lee et al., 2016). Therefore, the aim of the study was to
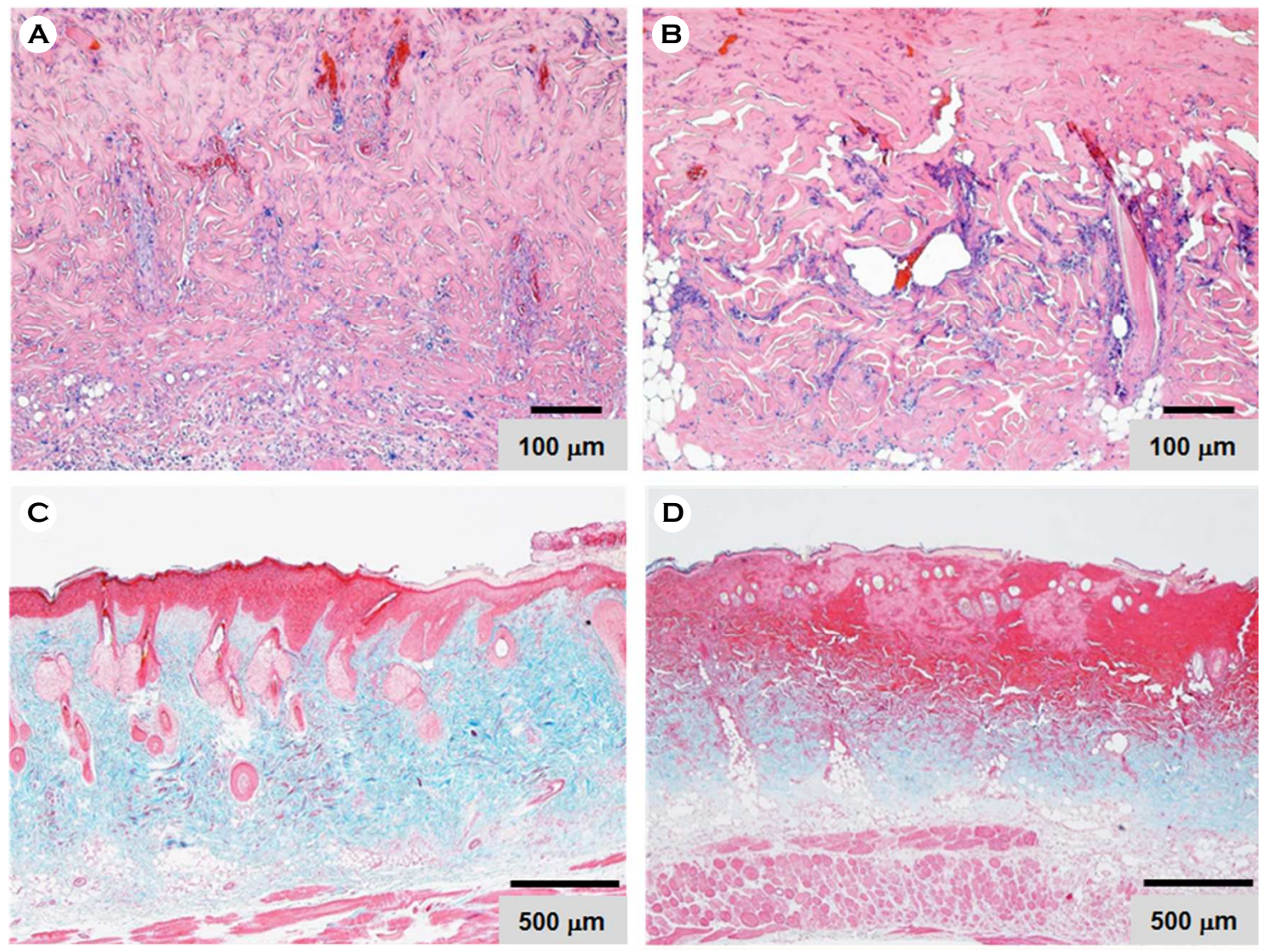

Fig. 2. Hematoxylin-eosin and Masson's trichrome staining. Representative histologic images of the skin flap day 7 post-surgery. FFPE tissues $(5 \mu \mathrm{m})$ were stained with hematoxylin-eosin or Masson's trichrome stain. (A) Hematoxylin-eosin slides from acai berry treated mice. (B) Hematoxylin-eosin slides of control mice. (C) Masson's trichrome slides from acai berry treated mice. (D) Masson's trichrome slides from control mice. Bars indicate either $100 \mu \mathrm{m}$ or $500 \mu \mathrm{m}$. Light green staining in the Masson's trichrome slides indicates collagen. Images were taken using a Nikon Eclipse 80i microscope and rendered on Adobe Photoshop. Total of 10 mice per group from two independent experiments. 
determine whether Euterpe oleracea Mart. could improve the survival of random-pattern skin flaps in mouse.

Freeze-dried acai berry powder was purchased from iHerb (organic acai powder, Navitas Organics, Novato, CA, USA). $200 \mathrm{~g}$ of acai berry powder was mixed in $400 \mathrm{~mL}$ of distilled water and boiled for $10 \mathrm{~min}$. Thereafter, $400 \mathrm{~mL}$ of $20 \%$ ethanol was added, shaken for $4 \mathrm{hr}$ at room temperature and the extract filtered through Whatman filter paper. The extract was lyophilized, frozen at $-20^{\circ} \mathrm{C}$ until usage. Eightweek-old, male ICR mice (25 30 gram) were purchased from Daehan Biolink (Eumseong, Chungcheongbukdo, Korea) and were provided with standard chow and water $\mathrm{ad}$ libitum. Animal experiments were conducted strictly within the guidelines of Institutional Animal Care and Use Committee of Kosin University College of Medicine (IACUC \#14-05). Random pattern skin flap elevation surgery was performed under anesthesia by intraperitoneal injection of $50 \mathrm{mg} / \mathrm{kg}$ of Zoletil (Virbac, Carros, France) and $5 \mathrm{mg} / \mathrm{kg}$ of xylazine (Rompun; Bayer Korea Inc., Korea). Hair from the dorsal area was removed using depilatory cream. A $3 \times 5 \mathrm{~cm}$ sized skin flap was vertically elevated from the panniculus carnosus layer, returned to the original location and the flap was sutured with a 4-0 nylon silk (Fig. 1). Following skin flap elevation, mice $(n=5)$ were given daily either acai berry extract per oral $(100 \mathrm{mg} / \mathrm{kg})$ or a PBS control for 7 days. Control mice $(n=5)$ were given PBS per oral. Mouse experi-
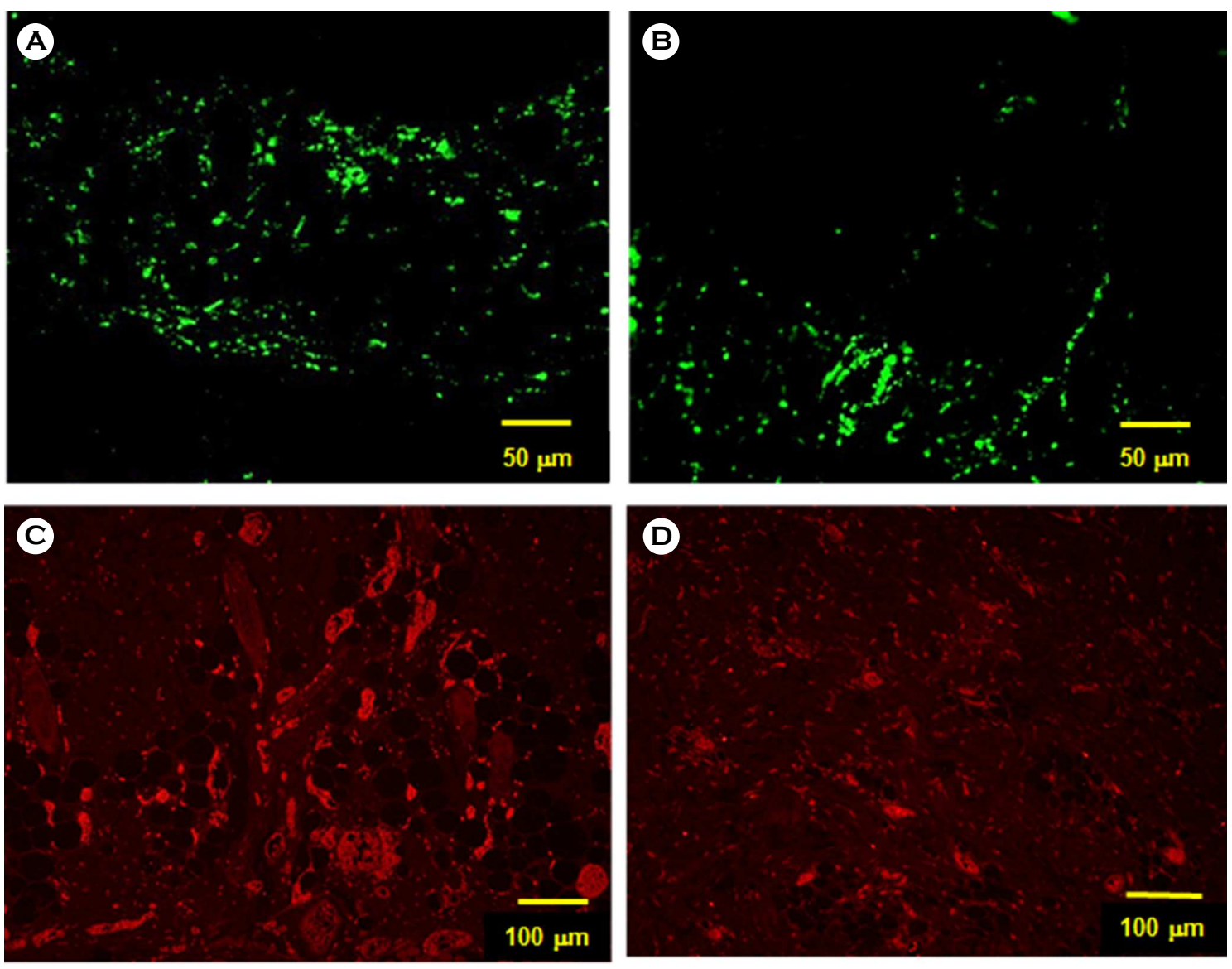

Fig. 3. Immunofluorescence staining of TGF- $\beta$ and VEGF. Representative immunofluorescence images of the skin flap day 7 post-surgery. FFPE tissues $(5 \mu \mathrm{m})$ were deparaffinized, treated with heat induced antigen retrieval reagents and stained with rabbit anti-TGF- $\beta$ or anti-VEGF polyclonal antibodies. Goat anti-rabbit IgG polyclonal antibodies conjugated with Alexa 488 or Alexa 594 were used as secondary antibodies. (A) TGF- $\beta$ positive cells (green) of acai berry treated mice. (B) TGF- $\beta$ positive cells of control mice. (C) VEGF positive signal (red) in slides of acai berry treated mice. (D) VEGF positive signal (red) in slides of control mice. Bars indicate either $50 \mu \mathrm{m}$ or $100 \mu \mathrm{m}$. Total of $10 \mathrm{mice}$ per group from two independent experiments. 
ments were repeated again for a total of ten mice per group.

On day 7 after surgery, mice were euthanized and formalinfixed paraffin embedded (FFPE) tissues of the border were stained with hematoxylin-eosin and Masson's trichrome using standard protocols (Lee et al., 2018). Histological evaluation showed infiltration of inflammatory cells less organized tissue structure in the control group compared to the acai berry treated group (Fig. 2A and 2B). The images were examined using the image $\mathbf{J}$ software and statistical analysis were performed using SPSS (PASW Statistics 18. 0, Chicago, IL, USA) statistical software. Data was expressed as the mean standard deviation. Differences between groups were analyzed by one-way ANOVA.

The collagen deposition was calculated to be $156764.9 \pm$ 20.6 pixels/high-power field in the acai berry treated group versus $87981.0 \pm 21.1$ pixels/high-power field in the control group (Fig. 2C and 2D) $(P<0.05)$. These results indicate that daily uptake of acai berry extract ameliorated infiltration of inflammatory cells and promoted collagen synthesis in the skin flap. To detect the presence of the anti-inflammatory cytokine TGF- $\beta$, FFPE sections were treated with heat induced antigen retrieval reagent and stained with polyclonal rabbit anti-TGF- $\beta$ Ab (Santa Cruz Biotechnology, Santa Cruz, CA, USA). Immunofluorescence results show more TGF- $\beta$ positive cells in the acai berry treated group compared to the control group (acai berry group, $83 \pm 9$ cells/highpower field; control group, $67 \pm 6$ cells/high-power field; $P<0.05$ ) (Fig. 3A and 3B). To detect the presence of VEGF (an angiogenic factor), FFPE tissues were stained with polyclonal rabbit anti-VEGF Ab (Santa Cruz Biotechnology, Santa Cruz, CA, USA). Immunofluorescence results show more VEGF signal in the acai berry treated group compared to the control group (acai berry group, 18101.3 \pm 10.5 pixels /high-power field; control group, $10539.0 \pm 6.9$ pixels/highpower filed; $P<0.05$ ) (Fig. 3C and 3D). Collectively, these results suggest that daily oral administration of acai berry extract in mice promotes healing of the skin flap, in part, due to induction of the anti-inflammatory cytokine TGF- $\beta$ and the angiogenesis factor VEGF.

The main cause of flap necrosis are inflammatory cell infiltration, generation of reactive oxygen species (ROS), capillary thrombus formation and decreased blood flow in the skin flap (Ohashi et al., 2007; Staiculescu et al., 2014). Therapeutic drugs such as anti-coagulants, phenothiazines, prostaglandin E1, deferoxamine, superoxide dismutase, dimethyl sulfoxide, allopurinol, $\mathrm{N}$-acetylcysteine and nitric oxide synthase inhibitors have all been used to promote wound healing (Cuzzocrea et al., 2000; Hsieh et al., 2014; Swartz et al., 2015). When tissue is subjected to hypoxia or endothelial damage, expression of the VEGF and transforming growth factor- $\beta$ (TGF- $\beta$ ) are up-regulated (Eming et al., 2007). Many studies have confirmed that VEGF and TGF- $\beta$ expression results in neovascularization, increased blood flow and subsequent improvements in tissue viability (Zhang et al., 2003; Chung et al., 2013). A recent report by de Mota et. al showed that extracts from acai berry seeds given orally enhanced microcirculation in skin flaps in hamsters (Coelho da Mota et al., 2018). Our data are consistent with these findings although the acai extract we used was from the whole fruit. We did not find any adverse effects on mice given the acai berry extracts (data not shown). In addition, in vitro cytotoxicity experiments using acai berry extracts and RAW264.7 cell lines exhibited no cytotoxic effects when treated at up to $1,000 \mu \mathrm{g} / \mathrm{mL}$ in a MTT assay (data not shown). This study confirms the positive effects of treatment with acai berry extract on the survival of random pattern skin flaps in mice. These results may represent a new therapeutic approach to enhancing flap viability and achieving faster wound repair. Further studies are needed to fully understand the benefit and limit of treatment with acai berry extract and wound healing.

\section{ACKNOWLEDGEMENT}

None

\section{CONFLICT OF INTEREST}

The authors have no conflicts of interest with regards to this study.

\section{REFERENCES}

Atalay C, Kockaya EA, Cetin B, Kismet K, Akay MT. Efficacy of topical nitroglycerin and transcutaneous electrical nerve stimulation on survival of random-pattern skin flaps in rats. 
Scandinavian Journal of Plastic and Reconstructive Surgery and Hand Surgery. 2003. 37: 10-13.

Cassidy A, Mukamal KJ, Liu L, Franz M, Eliassen AH, Rimm EB. High anthocyanin intake is associated with a reduced risk of myocardial infarction in young and middle-aged women. Circulation. 2013. 127: 188-196.

Chung KI, Kim HK, Kim WS, Bae TH. The effects of polydeoxyribonucleotide on the survival of random pattern skin flaps in rats. Archives of Plastic Surgery. 2013. 40: 181-186.

Coelho da Mota DS, Sicuro FL, Resende AC, De Moura RS, Bottino DA, Bouskela E. Effects of acai and cilostazol on skin microcirculation and viability of tram flaps in hamsters. Journal of Surgical Research. 2018. 228: 253-262.

Cuzzocrea S, Mazzon E, Costantino G, Serraino I, De Sarro A, Caputi AP. Effects of $n$-acetylcysteine in a rat model of ischemia and reperfusion injury. Cardiovascular Research. 2000. 47: 537-548.

Davis RE, Wachholz JH, Jassir D, Perlyn CA, Agrama MH. Comparison of topical anti-ischemic agents in the salvage of failing random-pattern skin flaps in rats. Archives of Facial Plastic Surgery. 1999. 1: 27-32.

Eming SA, Brachvogel B, Odorisio T, Koch M. Regulation of angiogenesis: Wound healing as a model. Progress in Histochemistry and Cytochemistry. 2007. 42: 115-170.

Ercocen AR, Apaydin I, Emiroglu M, Gultan SM, Ergun H, Yormuk E. The effects of 1-arginine and iloprost on the viability of random skin flaps in rats. Scandinavian Journal of Plastic and Reconstructive Surgery and Hand Surgery. 1998. 32: 19-25.

Hsieh CC, Hsieh SC, Chiu JH, Wu YL. Protective effects of $n$-acetylcysteine and a prostaglandin E1 analog, alprostadil, against hepatic ischemia: Reperfusion injury in rats. Journal of Traditional and Complementary Medicine. 2014. 4: 64-71.

Jurell G, Jonsson CE. Increased survival of experimental skin flaps in rats following treatment with antiadrenergic drugs. Scandinavian Journal of Plastic and Reconstructive Surgery and Hand Surgery. 1976. 10: 169-172.

Kerrigan CL. Skin flap failure: Pathophysiology. Plastic and Reconstructive Surgery. 1983. 72: 766-777.

Kjartansson J, Lundeberg T, Samuelson UE, Dalsgaard CJ, Heden P. Calcitonin gene-related peptide ( $c g r p$ ) and transcutaneous electrical nerve stimulation (tens) increase cutaneous blood flow in a musculocutaneous flap in the rat. Acta Physiologica Scandinavica. 1988. 134: 89-94.

Kryger Z, Zhang F, Dogan T, Cheng C, Lineaweaver WC, Buncke HJ. The effects of vegf on survival of a random flap in the rat: Examination of various routes of administration. British Journal of Plastic Surgery. 2000. 53: 234-239.

Lee CG, Jung J, Hwang S, Park CO, Hwang S, Jo M, Sin MH, Kim HH, Rhee KJ. Histological evaluation of bioresorbable threads in rats. Korean Journal of Clinical Laboratory Sciences. 2018. 20: 217-224

Lee JY, Kim N, Choi YJ, Nam RH, Lee S, Ham MH, Suh JH, Choi YJ, Lee HS, Lee DH. Anti-inflammatory and anti-tumorigenic effects of acai berry in Helicobacter felis-infected mice. Journal of Cancer Prevention. 2016. 21: 48-54.

Moura RS, Ferreira TS, Lopes AA, Pires KM, Nesi RT, Resende AC, Souza PJ, Silva AJ, Borges RM, Porto LC, Valenca SS. Effects of Euterpe oleracea mart. (acai) extract in acute lung inflammation induced by cigarette smoke in the mouse. Phytomedicine. 2012. 19: 262-269.

Mullen W, McGinn J, Lean ME, MacLean MR, Gardner P, Duthie GG, Yokota T, Crozier A. Ellagitannins, flavonoids, and other phenolics in red raspberries and their contribution to antioxidant capacity and vasorelaxation properties. Journal of Agricultural Food Chemistry. 2002. 50: 5191-5196.

Ohashi M, Tosa Y, Hosaka Y, Satoh K, Oguz Yeniduya M, Pang B. Reduction of ischemia-reperfusion injury to skin flap by treatment with monoclonal antibody to endothelial leukocyte adhesion molecule-1. Showa University Journal of Medical Sciences. 2007. 19: 137-145.

Pacheco-Palencia LA, Mertens-Talcott S, Talcott ST. Chemical composition, antioxidant properties, and thermal stability of a phytochemical enriched oil from acai (Euterpe oleracea mart.). Journal of Agricultural Food Chemistry. 2008. 56: 4631-4636.

Schauss AG, Wu X, Prior RL, Ou B, Patel D, Huang D, Kababick JP. Phytochemical and nutrient composition of the freezedried Amazonian palm berry, Euterpe oleraceae mart. (acai). Journal of Agricultural and Food Chemistry. 2006. 54: 8598 -8603 .

Smith DK, Dolan RW. Effects of vasoactive topical agents on the survival of dorsal skin flaps in rats. Otolaryngology - Head and Neck Surgery. 1999. 121: 220-223.

Staiculescu MC, Foote C, Meininger GA, Martinez-Lemus LA. The role of reactive oxygen species in microvascular remodeling. International Journal of Molecular Sciences. 2014. 15: 23792 -23835 .

Swartz JE, Aarts MC, Swart KM, Disa JJ, Gerressen M, Kuo YR, Wax MK, Grolman W, Braunius WW. The value of postoperative anticoagulants to improve flap survival in the free radial forearm flap: A systematic review and retrospective 
multicentre analysis. Clinical Otolaryngology. 2015. 40: 600 -609 .

Zhang F, Lei MP, Oswald TM, Pang Y, Blain B, Cai ZW, Lineaweaver WC. The effect of vascular endothelial growth factor on the healing of ischaemic skin wounds. British Journal of Plastic Surgery. 2003. 56: 334-341.
https://doi.org/10.15616/BSL.2019.25.3.282

Cite this article as: Jung S, Kim J, Kim EJ, Rhee KJ. Effect of Euterpe oleracea Mart. (acai berry) Extract on Skin Flap Survival in Mice. Biomedical Science Letters. 2019. 25: 282-287. 